\title{
NuClear Radiation Dose To The \\ Surroundings From Patients Who Are Undergoing Nuclear Medicine Examinations
}

\author{
Authors: Liv-Inger Stenstad, Operating Room of the Future, St. Olavs Hospital, \\ Trondheim, Norway liv-inger.stenstad@,stolav.no \\ Geir Andre Pedersen, Nuclear Medicine Department, St. Olavs Hospital, Trondheim, \\ Norway geir.andre.pedersen@,stolav.no \\ Andreas Dypvik Landmark, SINTEF Technology \& Society, Industrial \\ Management, Trondheim, Norway andreas.landmark@sintef.no \\ Berit Brattheim, Sør-Trøndelag University College, dept. of Radiography, Trondheim, Norway \\ berit.brattheim@hist.no
}

Corresponding author: Berit Brattheim, Sør-Trøndelag University College, Dept. of Radiography, Trondheim, Norway

E-mail: berit.brattheim@hist.no

PEER REVIEWED ARTICLE, VOL. 1, NR. 1, p. 11-18 PUBLISHED 27.11.2014

\section{Abstract}

The worldwide 2009 estimates for the average annual per-capita effective radiation dose from medicine have doubled during the past 15 years. This has increased the concern for patients as radiation sources. The existing evidence indicates that the amount of radiation is small; but there are few empirical studies with results documenting the actual extent. In this study, we examined the radiation from 48 patients undergoing nuclear medical examination. 20 patients were examined with bone scintigraphy, 20 underwent MUGA, while the remaining 8 went through octreotide scintigraphy procedure. At 0.25 meters from the patient, the radiation ranged from $31 \pm 9 \mu \mathrm{Svh}^{-1}$ for octreotide scintigraphy patients (111-In as agent), $69 \pm 13 \mu \mathrm{Svh}^{-1}$ for bone scintigraphy ( $99 \mathrm{mTc}$ ), to $92 \pm 26 \mu \mathrm{Svh}^{-1}$ for the MUGA patients ( $\left.99 \mathrm{mTc}\right)$. On the basis of these findings and others, one may consider current practices regarding waiting and using led shielding in areas where appropriate. Perhaps, and more important, these results could be used to improve patient and staff education. Better information material with more evidence will reduce undue anxiety.

Keywords: Nuclear medicine, radiation dose, radiation protection, radiopharmaceutical, nuclear medicine technologist, surroundings, quantitative research methodology 


\section{Introduction}

Conventional nuclear medicine procedures have seen a huge growth since the late 1970s. As of 2008, about 47000 out of 4.3 million imaging examinations performed in Norway involve nuclear medicine procedures (NRPA 2012). Estimates for 2009 suggest more than 3 billion medical procedures involving ionizing radiation are performed annually worldwide, of which close to 40 million represent nuclear medicine procedures (Mettler et al 2009). While this has led to important contributions to diagnosis and disease management, there are concerns about the rise in radiation dose associated with this growth. The worldwide 2009 estimates for the average annual per-capita effective radiation dose from medicine have doubled during the past 15 years (ibid.). Another associated concern is that patients administered with these radioisotopes become sources of exposure for hospital staff and accompanying family members.

In Norway, $90 \%$ of the annual population dose arises from CT and interventional radiology, while nuclear medicine examinations contribute to about 5\% (NRPA 2012). However, there is little evidence on exposure from patients undergoing diagnostic nuclear medicine procedures. The study of Konishi et al from 1994 (Konishi, Abe and Kusama 1994) reported that significant exposure from patients to staff was in practice limited to the day of administration. More recently, Bayram et al (2011) measured the dose received by employees in a range of nuclear medicine examinations at specified distances. The authors conclude that there was a marked reduction of radiation dose using lead protection and keeping greater physical distance from the patient, and that this should be the guideline for staff at nuclear medicine departments. Prior research as well as discussions with colleagues has uncovered that there is still uncertainty about the amount of exposure from patients and its possible impact on people accompanying the patients.

This paper reports first a study focusing on patient information about radiation exposure from patients undergoing nuclear medicine procedures. More specifically, the aim of this first step is to evaluate empirical values for the potential radiation dose from patients for three frequently used nuclear medicine procedures: bone scintigraphy (St. Olavs Hospital 2013), octreotide scintigraphy (ibid.), and MUGA (Multi-Gated Acquisition scan/radionuclide angiography) (ibid.).

\section{Material and Method}

Between February and March 2013 we selected the adult patients who were scheduled for MUGA, bone or octreotide scintigraphy at a Norwegian University Hospital. Both written and oral information were approached for patients.For participation, written consent was obtained.

Considering the patient as the source of radiation, we measured the radiation dose at four distances: $0.25 \mathrm{~m}, 0.5 \mathrm{~m}, 1 \mathrm{~m}$ and $2 \mathrm{~m}$, measured from the patients abdomen. We used Bayram et als survey (Bayram et al 2011) as a methodological guide for measuring the radiation dose from 
patients. All measurements was obtained with a hand held dosimeter: RadEye B20 from Thermo Scientific.

Radiation exposure was measured directly (within a minute) after injection for all three procedures. Measurements were than made after 30 minutes for MUGA, while the other patients were measured after two hours. Additionally the scintigraphy patients were equipped with pocket dosimeters also directly after injection (electronic personal dosimeter: EPD MK2+ from Thermo Scientific) for the duration of their stay. The pocket dosimeter is usually used for measuring the radiation coming from the surroundings, but turning the dosimeter inside out we measured the dose the person sends out to the surroundings. The dosimeters were worn in a lanyard around the neck, with the measurement detector on their abdomen, as figure 1 shows. The electronic dosimeters were calibrated when made in the factory, and we did not calibrate them again in the hospital before use.

When measuring the patient after injection with the hand held dosimeter, we measured the patient at the abdomen as mentioned above. The measurements were taken at four distances, and to obtain the correct distance, we used markings in the floor at $0.25 \mathrm{~m}, 0.50 \mathrm{~m}$, and $1 \mathrm{~m}$ and $2 \mathrm{~m}$. Se figure 1 for details.

Figure 1: How we measured the patient with the hand held dosimeter
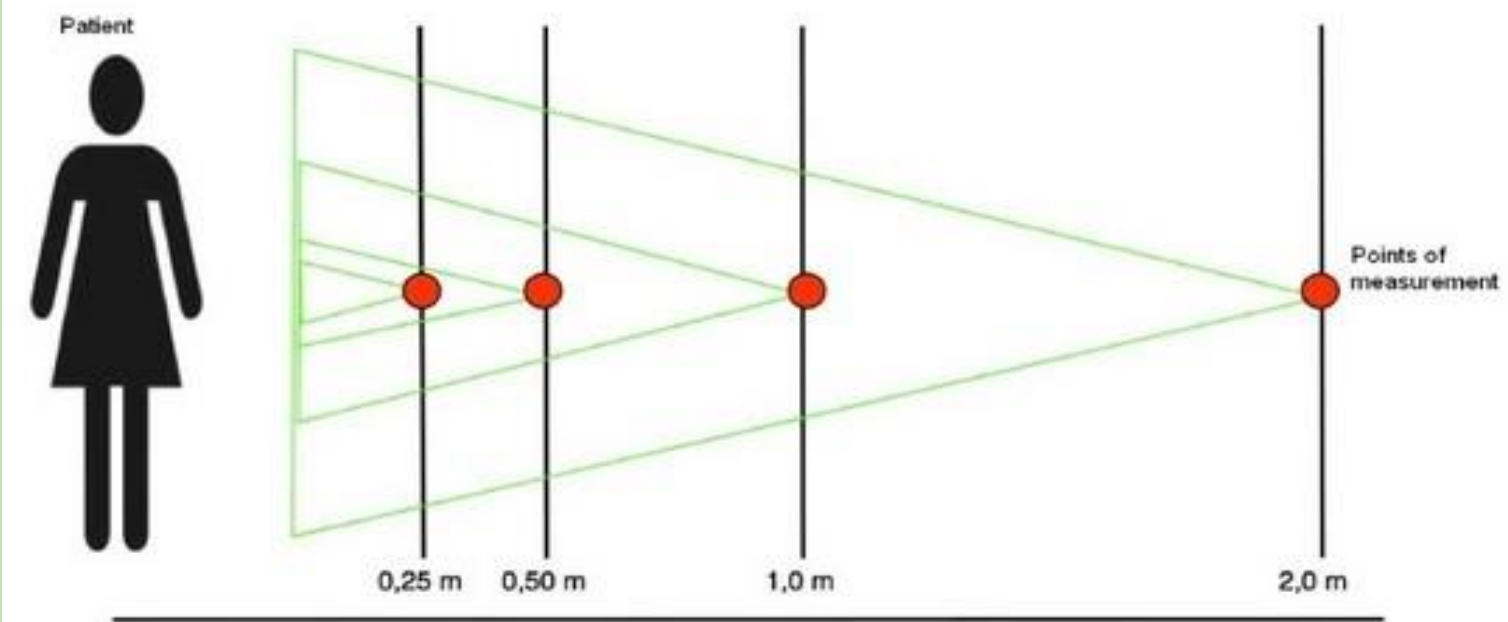

Data was collected on paper forms, punched and analyzed in Microsoft Excel. The study was approved by the Regional Committee for Medical Research Ethics

\section{Result:}


The mean dose rates $\left(\mu S_{v} \pm S D\right)$ as a function of distance for the three procedures are given in Table 1. At 0.25 meters from the patient, the radiation ranged from $31 \pm 9 \mu \mathrm{Svh}^{-1}$ for octreotide scintigraphy patients (111-In as agent), $69 \pm 13 \mu \mathrm{Svh}^{-1}$ for bone scintigraphy (99mTc), to $92 \pm 26$ $\mu \mathrm{Svh}^{-1}$ for the MUGA patients $(99 \mathrm{mTc})$. The decrease in radiation with distance follows the inverse square law.

Table 1: Rate in $\mu \mathrm{Sv} / \mathrm{h}$ from patients by examination and distance immediately after injection

\begin{tabular}{l|l|l|l|l}
\hline & $\begin{array}{l}\text { Distance } \\
\mathbf{0 , 2 5 m}\end{array}$ & $\mathbf{0 , 5 m}$ & $\mathbf{1 m}$ & $\mathbf{2 m}$ \\
\hline Examination & $69 \pm 13$ & $34 \pm 7$ & $16 \pm 3$ & $6 \pm 1$ \\
\hline Mone Scintigraphy (99mTc) & $92 \pm 26$ & $44 \pm 12$ & $19 \pm 4$ & $7 \pm 1$ \\
$\begin{array}{l}\text { Octreotide scintigraphy (111-In } \\
\text { Mean } \pm \text { SD) }\end{array}$ & $31 \pm 9$ & $15 \pm 3$ & $7 \pm 1$ & $2 \pm 0,5$ \\
\hline
\end{tabular}

Table 2 shows the mean and SD for the same patients, but measured after two hours (immediately before imaging). The rate now varied from $22 \pm 4 \mu \mathrm{Svh}^{-1}$ for octreotide scintigraphy, $40 \pm 11 \mu \mathrm{Svh}^{-1}$ to $81 \pm 24 \mu \mathrm{Svh}^{-1}$ for MUGA. For each procedure, there was considerable variation between patients and over time as indicated by the relatively big SD for MUGA and bone scintigraphy.

Table 2: Rate in $\mu \mathrm{Sv} / \mathrm{h}$ from patients by examination and distance 2 hours after injection

\begin{tabular}{l|l|l|l|l}
\hline & $\begin{array}{l}\text { Distance } \\
\mathbf{0 , 2 5 m}\end{array}$ & $\mathbf{0 , 5 m}$ & $\mathbf{1 m}$ & $\mathbf{2 m}$ \\
\hline Examination & $40 \pm 11$ & $20 \pm 7$ & $10 \pm 3$ & $4 \pm 1$ \\
\hline Bone Scintigraphy (99mTc) & $81 \pm 24$ & $36 \pm 12$ & $17 \pm 5$ & $6 \pm 1$ \\
\hline MUGA (99mTc) & $22 \pm 4$ & $11 \pm 2$ & $5 \pm 1$ & $2 \pm 0,5$ \\
$\begin{array}{l}\text { Octreotide scintigraphy (111-In } \\
\text { Mean } \pm \text { SD) }\end{array}$ & & & \\
\hline
\end{tabular}

Figure 2 shows the data collected from the dosimeters for the scintigraphy patients over the first 100 minutes after injection. 
Figure 2: Mean dosimeter reading for bone and octreotide scintigraphy patients

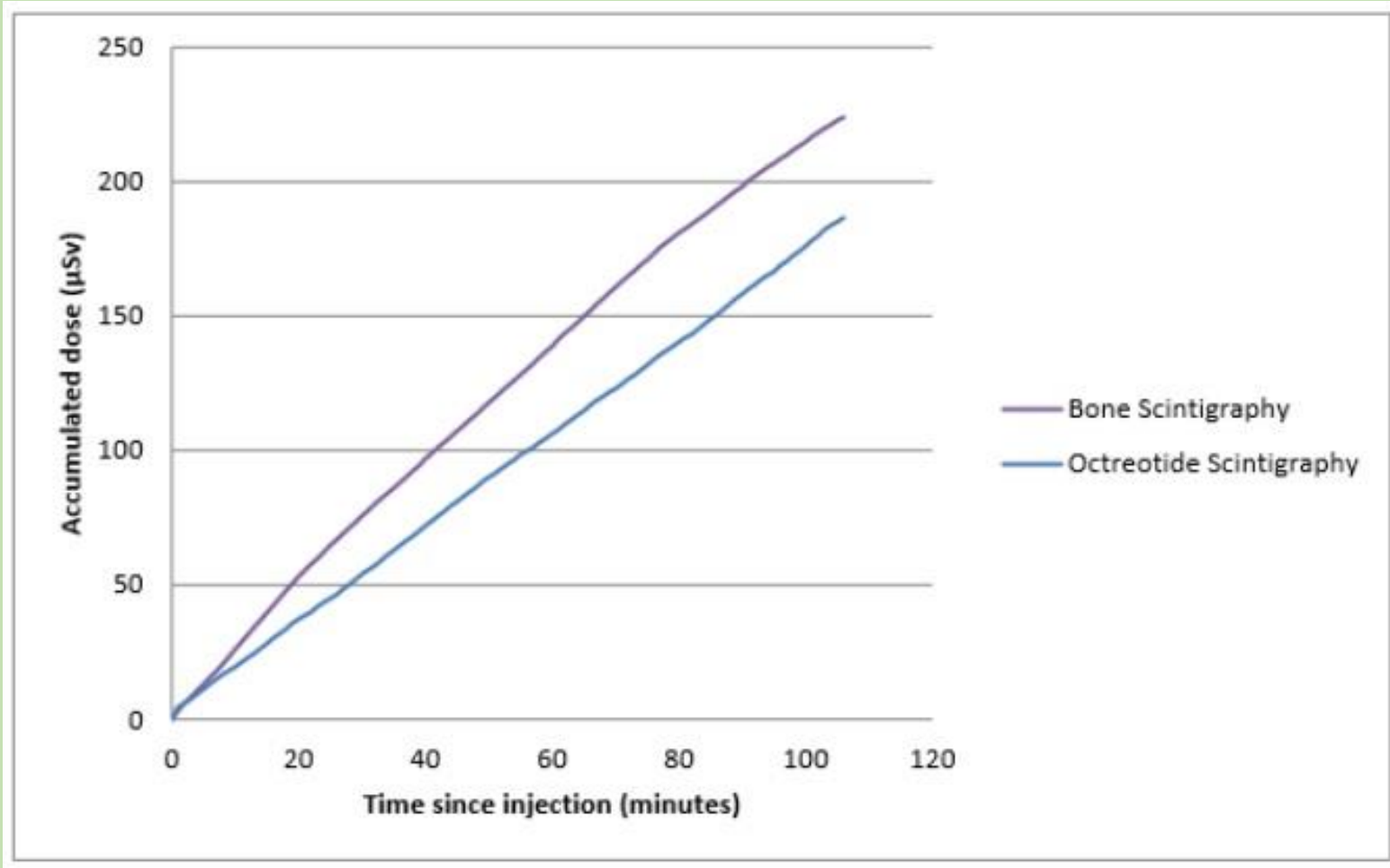

\section{Discussion:}

In this paper we focus on the dose that the patients submit to the environment as a whole, from the time of injection to the end of the examination. The findings are in line with previous studies (Mettler et al 2009, Konishi et al 1994, Bayram et al 2011 and Piwowarska-Bilska et al 2011) The radiation is most significant in the time immediately after injection. Our results reaffirm the conclusion from Konishi et al 1994 that "undue anxiety among hospital staff with regard to exposure to radioactive patients [and excreted urine from patients] must be placed in the proper perspective through education and training". However, we observed that significant anxiety was still present. Perhaps particularly amongst staff not directly involved in nuclear medicine procedures, but still in contact with the patients in other departments.

Better knowledge about radiation due to exposure from patients is important for deciding on reasonable and appropriate precautions against unnecessary radiation exposure for employees and next-of-kin. During the time between injection of a nuclear isotope and imaging, staff outside the nuclear facilities may be involved in the care of the patients, i.e. the patient might be moved to other departments for tests, ultrasound scanning, etc. Very often, a relative or a friend accompanies the patient to the different care activities. Empirically established values for the potential dose 
offered from patient at different conditions (distance, time, typical procedures) provides basis for better information about radiation levels to staff within and outside the nuclear ward as well as relatives accompanying the patient. It can also help promote personnel safety, allowing healthcare workers to make the necessary precautions needed to comply with the ALARA principles, as well as reduce undue anxiety.

Our research highlights the amount of radiation from such patients, and the nuclear medicine department could give other departments more precise information, with a more reasoned assessment of whether it is necessary to change practice or not. We want to contribute to more transparency and knowledge on the topic. There is another implication of the results, which pertains to the quality improvement issue, as it would be recommendable to monitor exposure dose from patients regularly as a means to build an empirical database for exposure safety purpose.

When it comes to the measurement of the dosages, the patients differ in how often they empty their bladder. Due to the fact of there might be uncertainty whether the patient emptied their bladder during the two hour waiting time between the injection and the scan, the result of the pocket dosimeter readings might been slightly affected by this if the radiation from the bladder reached the middle of the abdomen where the pocket dosimeter was placed. When measuring the patient with the handheld dosimeter before the scan, we measured before emptying the bladder.

\section{Conclusion}

We have established a numerical data set that can be used as a basis to conduct further investigation. Based on these findings and others, one may consider current practices regarding waiting and using led shielding in areas where appropriate. Perhaps, and more important, these results could be used to improve patient and staff education. Information material can be improved with more evidence in order to reduce undue anxiety. Furthermore, we conclude that the current practice is sufficient regarding shielding.

Based on this first step, we plan to examine the information practice about radiation exposure from patients at different hospitals to evaluate whether the information provided reflects the risk from the exposure. Additionally we wish to investigate patients perspectives on the information provided about the radiation dose. 


\section{Acknowledgement:}

We wish to thank the health carers and the patients who were willing to participate in the study. We would like to thank Professor Hans Olav Myhre and Jan Gunnar Skogås at Operating Room of the Future, St. Olavs Hospital, who provided all-round good advice during this research as well as feedback on this manuscript. We would also like to thank Marianne L. Stokkan and Jeanett Hoff at the Nuclear medicine dept. at St. Olavs Hospital for invaluable professional help.

\section{Conflict of interest statement}

None of the authors has any reported conflict of interest.

\section{Funding}

Funding by Sør-Trøndelag University College and St. Olavs Hospital.

\section{References}

Aalen, O O. (1994) Introduction to statistics - with medical examples (translated from

Norwegian: Innforing i Statistikk - Med Medisinske Ekesempler). Vol 2. Oslo: Ad Notam Gyldendal

Bayram, T, Yilmaz, A H, Demir, M og Sonmez, B (2011): Radiation Dose to Technologists per Nuclear Medicine Examination and Estimation of Annual Dose, Journal of Nuclear Medicine Technology, 39, pp 55-59.

Great Norwegian encyclopedia.(2007). Disintegration. Downloaded 23.05.13, from: http://snl.no/desintegrasjon

Great Norwegian encyclopedia. (2013). Indium. Downloaded 16.05.13, from: $\underline{\text { http://snl.no/indium }}$

ICRP. (2000). Annual Report-Pregnancy and medical irradiation. Publication 84. Konishi E, Abe K, Kusama T (1994): Urinary excretion and external radiation dose from patients administered with Radiopharmaceuticals. Journal of Radiation protection 
Mettler et al (2009): Radiological and Nuclear medicine Studies in the United States and Worldwide: frequency, radiation Dose, and Comparison with other Radiation Sources - 1950-2007. Journal of Radiology: Vol 253, No 2 (2009)

Leaflet Octreoscan ${ }^{\mathrm{TM}}$ from Mallinckrodt Pharmaceuticals, (01.06.2005).

Leaflet TechneScan ${ }^{\text {TM }}$ HDP from Mallinckrodt Pharmaceuticals, (24.07.2007).

Leaflet TechneScan ${ }^{\text {TM }}$ PYP from Mallinckrodt Pharmaceuticals, (20.12.1999).

Nuclear medicine dpt. St. Olavs Hospital, Trondheim.(2013). Procedure Bone Scintigraphy

Nuclear medicine dpt. St. Olavs Hospital, Trondheim.(2013). Procedure MUGA

Nuclear medicine dpt. St. Olavs Hospital, Trondheim.(2013). Procedure Octreotidscintigrafi

Norsk Lovtidend. (2013). Radiation Protection regulations (Norwegian: Strälevernforskriften - Norsk Lovtidend)

Downloaded 01:05.13, from http://www.lovdata.no/cgiwift/ldles?doc=/sf/sf/sf$\underline{20031121-1362 . h t m l}$

Piwowarska-Bilska H et al (2011): Occupational exposure at the Department of Nuclear Medicine as a work environment: A 19-year follow-up. Pol J Radiol. 2011 Apr-Jun; 76(2): 18-21.

Rootwelt, K. (2005). Nuklearmedisin 2. Utg. Oslo: Gyldendal Akademisk.

St. Olavs Hospital - MUGA (2012) Downloaded: 28.11.12, from:

http://www.stolav.no/no/Pasient/Undersokelse/Nuklearmedisinskeundersokelser/test/95527/

St. Olavs Hospital - Octreotidscintigrafi (2012) Downloaded 28.11.12, from:

http://www.stolav.no/no/Pasient/Undersokelse/Nuklearmedisinskeundersokelser/Octreotidsci ntigrafi/96635/

St. Olavs Hospital. (2012). (Eng: bone scintigraphy) Skjelettscintigrafi med/uten innlopsfase.

Downloaded 28.11.12, from:

http://www.stolav.no/no/Pasient/Undersokelse/Nuklearmedisinskeundersokelser/Skjelettscinti grafi/95506/

Radiography Open 2014 Vol. 1

ISSN: 2387-3345 
The Norwegian Radiation Protection Authority. (2012). Nuclear Medicine. Downloaded 28.11.12, from: http://www.nrpa.no/nukleaermedisin

The Norwegian Radiation Protection Authority. (2012). Riation doses and limits (translated from Norwegian: Stråledoser og Grenseverdier - Statens Strålevern). Downloaded 7.12.12, from: http://www.nrpa.no/eway/default.aspx?pid=239\&trg=Center 6304\&CenterAndRight 6254=63 04:0:15,4970:1:0:0:::0:0\&Center 6304=6312:80096::1:6322:3:::0:0

The Norwegian Radiation Protection Authority. (2018). Veileder 10 - om nuklearmedisin Downloaded 03.05.13, from http://www.nrpa.no/dav/6a19fd74c1.pdf

US EPA. (2013). Technetium-99| Radiation Protection| Downloaded:16.05.13, from http://www.epa.gov/radiation/radionuclides/technetium.html

User Manual Electronic personal dosimeter: EPD MK2+ fra Thermo Scientific User Manual Handheld dose meter: RadEye B20 fra Thermo Scientific 